Tohoku J. exp. Med., 1981, 133, 451-456

\title{
Lipid Composition of Adipose Tissue from "Membranous Lipodystrophy"
}

\author{
Masayuki Tokunaga, Eikichi Wakamatsu, Masamitsu Sato, \\ Osamu Namiki,* Atsunobu Yokosawa and \\ Masakichi MotomiYa $\dagger$ \\ Department of Orthopedic Surgery, Tohoku University School \\ of Medicine, Sendai 980, *Department of Orthopedic Surgery, \\ Tokyo Womens Medical College, Tokyo 162, and †the Research \\ Institute for Tuberculosis and Cancer, Tohoku University, \\ Sendai 980
}

Tokunaga, M., Wakamatsu, E., Sato, M., Namiki, O., Yokosawa, A. and Мотомгуа, M. Lipid Composition of Adipose Tissue from "Membranous Lipodystrophy". Tohoku J. exp. Med., 1981, 133 (4), 451-456-The lipid composition of the adipose tissue from the bone marrow and that of the subcutaneous depot fat of four patients of membranous lipodystrophy were investigated. It was found that the lipid composition of the samples from the cases of membranous lipodystrophy was almost similar to that in controls. Also discussions were made on mechanism related to the accumulation of abnormal depot fat.

lipids; lipomatosis; bone marrow; membranous lipodystrophy

Membranous lipodystrophy was first described as a pathological entity by Nasu et al. (1973). Its characteristics consist of cystic dysplasia in the long bone, membranous structures not only in the bone marrow but also in the adipose tissue, and of sudanophilic leucodystrophy of the cerebrum. About 30 cases of membranous lipodystrophy have been reported up to the present in Japan (Sato et al. 1976; Tashiro et al. 1976; Akai et al. 1977). On the other hand, Hakola (1972) reported 9 patients with the signs and symptoms almost similar to those of membranous lipodystrophy and diagnosed them as lipomembranous polycystic osteodysplasia. These two diseases are likely to belong to the same entity as evaluated by clinicopathological findings. Up to the present, disturbance of lipid metabolism has been suggested as a cause of membranous lipodystrophy. However, there have been only a few reports on the detailed analysis of lipids from the membranous lipodystrophy (Nasu et al. 1973; Tashiro et al. 1976). The present paper deals with the analysis of lipid composition of the adipose tissue of four cases of membranous lipodystrophy together with relevant chemical and laboratory data.

Received for publication, July 3, 1980.

M. Tokunaga's present address: Department of Orthopedic Surgery, Tohoku Teishin Hospital, Yamatomachi 2-29-1, Sendai 983. 


\section{Clinical}

The details of the clinicopathological finding of the four cases of the membranous lipodystrophy in the present communication were published elsewhere (Sato et al. 1976). Hence only a brief summary of the clinical and laboratory data will be presented here. Table 1 shows the history and results of the neuro-psychiatric evaluation of the above four cases. The principal histological changes in the bone were atrophy and cystic radiolucency. As shown in Table 2 cholesterol was somewhat lower and the $\beta$-lipoprotein level was somewhat higher than usual in Cases 3 and 4 . The serum lipase level as determined by the method of Tietz and Fiereck (1966) was somewhat higher than usual in Case 4. Other laboratory data were almost within normal limits.

TABLE 1. Clinical data of the patients with membranous lipodystrophy

\begin{tabular}{ccccccc}
\hline Case No. & Sex & $\begin{array}{c}\text { Age at the } \\
\text { first } \\
\text { examination }\end{array}$ & $\begin{array}{c}\text { Year of the } \\
\text { first } \\
\text { examination }\end{array}$ & $\begin{array}{c}\text { History of } \\
\text { repeated } \\
\text { fracture }\end{array}$ & $\begin{array}{c}\text { Mental } \\
\text { disturbance }\end{array}$ & Outcome \\
\hline 1 & F & 41 & 1970 & + & None & $\begin{array}{c}\text { Suicide at the } \\
\text { age of } 43\end{array}$ \\
2 & M & 29 & 1970 & + & Epilepsy & $\begin{array}{c}\text { Death at the } \\
\text { age of } 30\end{array}$ \\
3 & M & 19 & 1973 & + & Euphoria & Alive \\
4 & M & 19 & 1974 & + & Euphoria & Alive \\
\hline
\end{tabular}

TABLE 2. Results of quantitation of lipids, lipase and lipoprotein in serum

\begin{tabular}{lcccc}
\hline & Case 1 & Case 2 & Case 3 & Case 4 \\
\hline Total lipid $(\mathrm{mg} / \mathbf{1 0 0 \mathrm { ml } )}$ & - & - & 497 & 359 \\
Total cholesterol $(\mathrm{mg} / \mathbf{1 0 0} \mathrm{ml})$ & 130 & 160 & 193 & 157 \\
Cholesterol ester $(\mathrm{mg} / \mathbf{1 0 0} \mathrm{ml})$ & - & - & 68 & 77 \\
Neutral fat $(\mathrm{mg} / \mathbf{1 0 0} \mathrm{ml})$ & 105 & 62 & 99 & 66 \\
Phospholipid $(\mathrm{mg} / \mathbf{1 0 0} \mathrm{ml})$ & 159 & 140 & 209 & 177 \\
Free fatty acid $(\mathrm{mEq} / \mathrm{liter})$ & - & - & 0.41 & 0.44 \\
Lipase* & - & - & 0.6 & 1.6 \\
$\boldsymbol{\alpha}$-Lipoprotein & - & - & 17.9 & 21.8 \\
Pre $\beta+\beta$-lipoprotein & - & - & 77.0 & 74.1 \\
\hline
\end{tabular}

* Determined by the method of Tietz and Fiereck (1966).

\section{Experimental}

Materials. The specimens from the bone marrow and from the subcutaneous depot fat of the cases of membranous lipodystrophy were obtained by operation. The operation comprised curettage of the bone marrow and the yellow-brown colored adipose tissue therein, and subsequent bone grafting.

Fractionation of lipids. All the samples were frozen immediately after operation and kept at $-20^{\circ} \mathrm{C}$ until used for biochemical analysis. The fraction of lipid was freed from non-lipid contaminations as described by Folch et al. (1957), concentrated in vacuo and was dried completely in a desiccator.

Thin layer chromatography. Samples were applied on $20 \times 20 \mathrm{~cm}$ plates of Silicagel G (Merck). Irrigation on Silicagel G for the detection of glycolipid was effected in a solvent system of chloroform: methanol: water $(65: 25: 4)$ (solvent 1). Detection was made with anthron reagent (Roe 1955). For the chromatographic seperation of sphingolipids, irrigation was effected in a solvent system of chloroform: methanol:water $(60: 35: 8)$ (solvent 2). Detection was made by the reagent of Dittmer and Lester (1964). Irrigation in a solvent 
system of petroleum ether: ether: acetic acid $(80: 20: 1)$ (solvent 3) was carried out for the separation of lipids by classes. Thereafter the plates were sprayed within $50 \% \mathrm{H}_{2} \mathrm{SO}_{4}$ and charred for revelation of spots. In two-dimensional thin layer chromatography for the detection of sphingolipids, the first run was effected in solvent 3 and the second in solvent 1. For the quantitative determination of different classes of lipids, the plates after irrigation in solvent 3 were sprayed with water and the band corresponding to each class of lipids was eluted with a 2:1 mixture of chloroform and methanol and ether. The eluate was dried and the ratio of individual fraction was determined by gravity.

Gas chromatography of fatty acids. Samples were hydrolyzed with $0.5 \mathrm{~N} \mathrm{KOH}$ in $55 \%$ ethanol. This saponification mixture received an addition of $2 \mathrm{~N} \mathrm{HCl}$. The acidified aqueous phase was extracted with petroleum ether. The organic phase was repeatedly washed with water, dried with $\mathrm{Na}_{2} \mathrm{SO}_{4}$ and was used for the preperation of the methyl ester of fatty acid in the reaction with diazomethane. A gas chromatograph (JCG-750, JEOL Co.) equipped with a hydrogen-flame ionization detector was used for the detection and tentative identification for fatty acids based on the equivalent chain length method throughout this series of experiments. (The temperature of a $2-\mathrm{m}$ column of $1 \%$ diethylenglycol succinate (DEGS) on Chromosorb W was kept at $200^{\circ} \mathrm{C}$ and the pressure of the carrier gas $0.7 \mathrm{~kg} / \mathrm{cm}^{2}$.) For the identification of hydroxy fatty acids, a mixture of methyl esters of fatty acids was chromatographied on a plate of Silicagel G in a solvent system of $n$-hexane: ethyl ether $(60: 40)$ (solvent 4). 2-OH-methyl myristate were used as references of hydroxy fatty acids. Detection was made by spraying a $0.01 \%$ solution of Rhodamine B (10 ml of a $0.1 \%$ ethanolic solution of Rhodamine B mixed with $90 \mathrm{ml}$ of a $0.25 \mathrm{M}$ solution of $\mathrm{NaH}_{2} \mathrm{PO}_{4}$ ).

\section{Results}

After irrigation in solvent 1, no spot of glycolipids could be detected with anthron reagent even when $1 \mathrm{mg}$ of the lipid fraction was applied. After irrigation in solvent 2, a faint spot which had the same Rf as that of phosphatidyl choline from egg yolk was detected. However, the quantity of the phospholipid by visual evaluation of the charred chromatogram was very small as compared with that of the other-than-phospholipid.

TABLE 3. Lipid classes detected in specimens from the cases of membranous lipodystrophy

\begin{tabular}{|c|c|c|c|c|c|c|c|c|c|c|}
\hline & $\begin{array}{c}\text { Case } 1 \\
\text { BM, f, } \\
43 y^{*}\end{array}$ & $\begin{array}{l}\text { Case } 1 \\
\mathrm{SC}, \mathrm{f} \\
43 \mathrm{y}\end{array}$ & $\begin{array}{c}\text { Case } 2 \\
\mathrm{BM}, \mathrm{m} \text {, } \\
31 \mathrm{y}\end{array}$ & $\begin{array}{c}\text { Case } 3 \\
\text { BM, m, } \\
21 \mathrm{y}\end{array}$ & $\begin{array}{c}\text { Case } 4 \\
\mathrm{SC}, \mathrm{m} \text {, } \\
20 \mathrm{y}\end{array}$ & $\begin{array}{c}\text { Control } \\
1 \\
\mathrm{SC}, \mathrm{m}, \\
8 \mathrm{y}\end{array}$ & $\begin{array}{c}\text { Control } \\
1 \\
\text { BM, m, } \\
8 \mathrm{y}\end{array}$ & $\begin{array}{c}\text { Control } \\
2 \\
\mathrm{SC}, \mathrm{f} \\
42 \mathrm{y}\end{array}$ & $\begin{array}{c}\text { Control } \\
3 \\
\mathrm{SC}, \mathrm{m}, \\
24 \mathrm{y}\end{array}$ & $\begin{array}{c}\text { Control } \\
4 \\
\mathrm{BM}^{2} \mathrm{~m}, \\
25 \mathrm{y}\end{array}$ \\
\hline CHE (\%) & 6.7 & 3.6 & 3.7 & 8.1 & 3.1 & 0.7 & 3.8 & 2.5 & 5.7 & 4.9 \\
\hline TG $\%$ & 54.7 & 42.8 & 63.0 & 57.6 & 57.6 & 93.2 & 70.6 & 63.0 & 60.2 & 54.2 \\
\hline FFA $(\%)$ & 5.6 & 6.8 & 8.6 & 7.8 & 5.6 & 1.6 & 4.9 & 4.0 & 6.2 & 5.6 \\
\hline $\mathrm{DG}(\%)$ & 12.5 & 14.0 & 8.0 & 12.1 & 20.2 & 1.6 & 9.3 & 9.8 & 9.2 & 14.2 \\
\hline $\mathrm{CH} \quad(\%)$ & 8.2 & 15.2 & 5.2 & 6.8 & 3.0 & 1.3 & 6.2 & 8.4 & 8.4 & 14.2 \\
\hline Other $(\%)$ & 12.9 & 17.6 & 11.5 & 7.6 & 16.0 & 1.5 & 5.2 & 12.3 & 9.8 & 6.9 \\
\hline $\begin{array}{c}\text { Total } \\
\text { lipid }(\%)\end{array}$ & 45.1 & 28.6 & 37.5 & - & - & - & - & 27.6 & 56.2 & 10.2 \\
\hline
\end{tabular}

CHE, cholesterol ester; TG, triglyceride (simple lipid); FFA, free fatty acid; DG, diglyceride; $\mathrm{CH}$, cholesterol; Other, other components (unidentified). BM, bone marrow; SC, subcutaneous depot fat.

Separation by thin layer chromatography in a solvent system of petroleum ether: ether: acetic acid $(80: 20: 1)$.

Determination of the ratio of individual lipid classes by gravimetry.

$*_{f}, 43 y=$ female, 43-year-old. 
Quantitation of lipids eluted from the chromatogram after irrigation in solvent 3 indicated that of the lipid classes detected (cholesterol ester, triglyceride, free fatty acids, diglyceride and cholesterol). Triglyceride was the major component (Table 3). Also it was found that the composition of the lipid classes from the samples of the cases of membranous lipodystrophy was almost similar to that of the controls.

In two-dimentional chromatography no sphingolipid could be detected. Irrigation in solvent 4 failed to reveal any $\mathrm{OH}$-fatty acid.

There was a case-to-case difference in the fatty acid composition of triglycerides (simple lipid) of the cases of membranous lipodystrophy. However,

TABLE 4. Fatty acid composition of simple lipids (triglycerides)

\begin{tabular}{|c|c|c|c|c|c|c|c|c|c|}
\hline & $\begin{array}{c}\text { Case } 1 \\
\text { SC, f, } \\
43 y^{*}\end{array}$ & $\begin{array}{c}\text { Case } 2 \\
\text { BM, m, } \\
31 y\end{array}$ & $\begin{array}{c}\text { Case } 3 \\
\mathrm{BM}, \mathrm{m}, \\
21 \mathrm{y}\end{array}$ & $\begin{array}{c}\text { Case } 4 \\
\mathrm{SC}, \mathrm{m}, \\
20 \mathrm{y}\end{array}$ & $\begin{array}{c}\text { Control } 1 \\
\mathrm{SC}, \mathrm{m}, \\
8 \mathrm{y}\end{array}$ & $\begin{array}{c}\text { Control } 1 \\
\text { BM, m, } \\
8 \mathrm{y}\end{array}$ & $\begin{array}{l}\text { Control } 2 \\
\text { SC, f, } \\
42 \mathrm{y}\end{array}$ & $\begin{array}{c}\text { Control } 3 \\
\mathrm{SC}, \mathrm{m}, \\
24 \mathrm{y}\end{array}$ & $\begin{array}{c}\text { Control } 4 \\
\mathrm{BM}, \mathrm{m}, \\
25 \mathrm{y}\end{array}$ \\
\hline $13: 0 \dagger$ & & 0.3 & & & 0.2 & & 0.3 & & \\
\hline $14: 0$ & 1.2 & 4.8 & 9.4 & 11.7 & 1.7 & 2.4 & 2.9 & 2.4 & 1.6 \\
\hline $14: 1$ & 0.5 & 1. 7 & 1.3 & 0.3 & 0.6 & 0.9 & 0.8 & 0.9 & \\
\hline $16: 0$ & 29.1 & 20.7 & 46.1 & 58.3 & 24.3 & 21.6 & 26.8 & 21.0 & 26.3 \\
\hline $16: 1$ & 19.3 & 15.5 & 12.2 & 4. 2 & 10.5 & 7. 2 & 12.9 & 7.2 & 9.8 \\
\hline $16: 2$ & & & & & 0.3 & 0.4 & 0.8 & 0.4 & \\
\hline 18:0 & 0.5 & 1.4 & 7.3 & 4.7 & 1.1 & 1.3 & 0.8 & 1.3 & 3.1 \\
\hline $18: 1$ & 42.3 & 52.0 & 25.1 & 16.1 & 56.7 & 58.2 & 39.4 & 58.2 & 58.9 \\
\hline $18: 2$ & 7.1 & 2.6 & & & 4.2 & 6.6 & 14.4 & 6.6 & 3.5 \\
\hline $20: 0$ & & 1.0 & & & 0.4 & 2.0 & 0.9 & 2.0 & 1.8 \\
\hline
\end{tabular}

* $\mathrm{f}, 43 \mathrm{y}=$ female, 43 -year-old. SC, subcutaneous depot fat; BM, bone marrow.

$\dagger$ The number of carbon atoms: the number of double bonds. For example, 16:0 is hexadecanoic acid (palmitic acid) and 18:2 is octadecadienoic acid.

TABLE 5. Composition of fatty acids from cholesterol ester

\begin{tabular}{ccccc} 
Case 1 & $\begin{array}{c}\text { Case 1 } \\
\text { BM, f, 43y* }\end{array}$ & $\begin{array}{c}\text { Control 1 } \\
\text { SC, f3y }, 8 y\end{array}$ & $\begin{array}{c}\text { Control 1 } \\
\text { BM, m, 8y }\end{array}$ \\
\hline $14: 0$ & 6.0 & 12.0 & 1.1 \\
$14: 1$ & 1.2 & 0.5 & 3.5 \\
15.0 & & & \\
$15: 1$ & 41.0 & 60.0 & 63.5 \\
$16: 0$ & 11.6 & 6.9 & 15.9 \\
$16: 1$ & & & 1.8 \\
$17: 0$ & & 4.9 & 1.8 \\
$18: 0$ & 7.1 & 15.7 & 1.0 \\
$18: 1$ & 31.5 & & 1.0 \\
$19: 0$ & 1.6 & & 8.5 \\
20.0 & & & 1.8
\end{tabular}

After saponification with ethanolic KOH. Preparation of methyl ester with diazomethane. Gas-chromatographic analysis as in Table 4. Samples from Control 1 BM and Control 1 SC were united and used for analysis because only a small amount of material was available.

${ }^{*} \mathrm{f}, 43 \mathrm{y}=$ female, 43-year-old; SC, subcutaneous depot fat; BM, bone marrow.

Gas-chromatographic analysis of the fatty acids from other samples could not be carried out because of the limited amount of material. 
TABLE 6. Composition of free fatty acids

\begin{tabular}{ccccc} 
& $\begin{array}{c}\text { Case 1 } \\
\text { SC, f. 43y }\end{array}$ & $\begin{array}{c}\text { Case 1 } \\
\text { BM, f, 43y }\end{array}$ & $\begin{array}{c}\text { Control 1 } \\
\text { SC, m, 8y }\end{array}$ & $\begin{array}{c}\text { Control 1 } \\
\text { BM, m, 8y }\end{array}$ \\
\cline { 3 - 4 } $14: 0$ & 6.2 & 11.4 & 4.7 & 4.7 \\
$14: 1$ & 1.7 & 4.2 & 0.3 & 1.9 \\
$15: 0$ & 1.7 & & & \\
$15: 1$ & & & & \\
$16: 6$ & 46.8 & 58.8 & 58.6 & 49.3 \\
$16: 1$ & 3.9 & 2.6 & 4.7 & 0.7 \\
$17: 0$ & 2.9 & 4.2 & 0.1 & 0.4 \\
$17: 1$ & 0.8 & & 2.3 & 9.4 \\
$18: 0$ & 15.8 & 7.0 & 3.5 & 11.2 \\
$18: 1$ & 12.2 & 10.4 & 25.8 & \\
$19: 0$ & 4.0 & 1.4 & & \\
$19: 1$ & 4.0 & & & \\
\hline
\end{tabular}

Preparation of methyl ester with diazomethane. Gas-chromatographic analysis as in Table 4. SC, subcutaneous depot fat; BM, bone marrow. Gas-chromatographic analysis of fatty acids from other samples could not be carried out because of the limited amount of material.

the data, as a whole, were similar to those of the control specimens. Both in samples from the cases of membranous lipodystrophy and in those from the controls, palmitic acid (hexadecanoic acid) and octadecamonoenoic acid were the major constituents (Table 4). No pattern characteristic of membranous lipodystrophy could be confirmed. No difference was found either in fatty acid composition of cholesterol ester (Table 5) or that of free fatty acids (Table 6) between the samples of membranous lipodystrophy (Cases 3 and 4) and control specimens.

\section{Discussion}

The yellow bone marrow in animals which is the important depot fat reflects the functional and metabolic status of the host (Lund et al. 1962). Usually the fatty acid composition of the yellow bone marrow is similar to that of the adipose tissue of the same individual (Zakaria and Shafrir 1976). The lipid in the normal bone marrow primarily consists of triglyceride (simple lipids) that amounts to as high as 96 to $98 \%$ of the total lipids according to Zach (Zakaria) and Shafrir (1974). Since the depot fat of an organism shows an almost similar pattern with respect to composition of lipid irrespective of age (Krut and Bronte-Stewart 1964), the control specimens were taken from the subjects whose ages were somewhat different from those of the four cases of membranous lipodystrophy in the present study. It was found that the relative ratio of triglyceride in the present experiments was mostly lower than the ratio reported in the literature by other investigators. None the less it was the principal constituent of the lipids. It has been accepted that palmitic acid and octadecamonoenoic acid (oleic acid) are the major constituents of the fatty acids of simple lipid in bone marrow and depot fat (Hefferman 1963; Zach and Shafrir 1974). In the report of Lund et al. (1962) the percentage of palmitic acid was $26 \%$ and that of octadecamonoenoic acid (oleic 
acid) was $46 \%$. Oleic acid was the major fatty acid according to Hefferman (1963). Our results were almost in agreement with the results of the above investigators. Thus no chemical data suggestive of the findings that are characteristics of membranous lipodystrophy could be detected.

On the other hand, a histological study has revealed the presence of membranous structures. This finding has been ascribed to the inability of the fatty cells to maintain their structual integrity (Sato et al. 1976). Accumulation of unusual lipids in the bone marrow may be due to the lack of lipase or to an excess of hydroxy fatty acids. In our study, however, no evidence for the presence of hydroxy fatty acids could be obtained. Further chemical studies are required in order to arrive at conclusion concerning the pathogenesis of membranous lipodystrophy.

\section{References}

1) Akai, M., Tat eishi, A., Cheng, C.H., Morii, K., Abe, M., Ohno, T. \& Ben, M. (1977) Membranous lipodystrophy. A clinicopathological study of six cases. J. Bone Joint Surg., 59-A, 802-809.

2) Dittmer, J.C. \& Lester, R.C. (1964) A simple, specific spray for the detection of phospholipids on thin-layer chromatograms. J. Lipid Res., 5, 126-127.

3) Folch, J., Lees, M. \& Sloane Stanley, G.H. (1957) A simple method for the isolation and purification of total lipids from animal tissues. J. biol. Chem., 226, 497-509.

4) Hakola, A.H.P. (1972) Neuropsychiatric and genetic aspects of a new hereditary disease characterized by progressive dementia and lipomembranous polycystic osteodysplasia. Acta psychiat. scand., Suppl. 232, 1-173.

5) Hefferman, A.G.A. (1963) The fatty acid composition of human adipose tissue. Clin. Sci., 25, 423-429.

6) Krut, L.H. \& Bronte-Stewart, B. (1964) The fatty acids of human depot fat. J. Lipid Res., 5, 343-351.

7) Lund, P.K., Abadi, D.M. \& Mathies, J.C. (1962) Lipid composition of normal human bone marrow as determined by column chromatography. J. Lipid Res., 3, 95-98.

8) Nasu, T., Tsukahara, Y. \& Terayama, K. (1973) A lipid metabolic disease - "membranous lipodystrophy" - an autopsy case demonstrating numerous peculiar membrane-structures composed of compound lipid in bone and bone marrow and various adipose tissues. Acta path. jap., 23, 539-558.

9) Roe, J.H. (1955) The determination of sugar in blood and spinal fluid with anthrone reagent. J. biol. Chem., 212, 335-343.

10) Sato, M., Chiba, T., Tokunaga, M., Funayama, K. \& Sakurai, M. (1976) Clinical study on membranous lipodystrophy. Orthop. Surg., 27, 1575-1582.

11) Tashiro, M., Koide, T., Watanabe, Y., Maruya, M. \& Satomi, K. (1976) "Membranous lipodystrophy (Nasu)" as a lipid metabolic disease. Clin. orthop. Surg., 11, 614-625.

12) Tietz, N.W. \& Fiereck, E.A. (1966) A specific method for serum lipase determination. Clin. chim. Acta, 13, 352-358.

13) Zach (Zakaria), E. \& Shafrir, E. (1974) Composition of bone marrow adipose tissue in relation to body fat depots in various species. Isr. J. med. Sci., 10, 1541-1550.

14) Zakaria, E. \& Shafrir, E. (1976) Yellow bone marrow as adipose tissue. Proc. Soc. exp. Biol. Med., 124, 1265-1268. 